\title{
'Hospice' versus 'hospital' care-re-evaluation after 10 years as seen by surviving spouses
}

\author{
C. MURRAY PARKES \\ M.D., F.R.C.Psych., D.P.M. \\ JENNY PARKES \\ B.Sc. \\ Academic Department of Psychiatry, The London Hospital Medical College, London E1
}

\begin{abstract}
Summary
This study compares terminal cancer care in 1967-69 with care in 1977-79 as evaluated by surviving spouses of patients who died in St Christopher's Hospice and other local hospitals.

Patients and their surviving spouses reported less personal distress in both settings in 1977-79 than in 1967-69 and the patients were also thought to have suffered less pain. These differences were found before, during and, in surviving spouses, after the period of terminal care. They were confirmed in subsamples of 30-34 patients matched for age, sex, socio-economic status and duration of terminal period.

Improvements may be attributable to the training in terminal care provided by staff of the Hospice since 1967 and augmented in its Study Centre which was opened in 1973.

Although pain and distress in the patient is no longer a major problem in either setting, spouses in 1977-79 remain less anxious at St Christopher's Hospice than at other hospitals; they play a larger part in the care of the patient and are in closer contact with staff before and after bereavement.
\end{abstract}

KEY WORDS: hospice, terminal care, cancer, pain, thanatology.

\section{Introduction}

The hospice movement, with its emphasis on support for patients and families and its methods of symptom control, has had a worldwide influence on the care of the dying since the inception of St Christopher's Hospice, Sydenham in 1967. Despite this, few attempts have been made to carry out systematic evaluation of the overall effects of hospice care.

Parkes (1979) compared assessments by spouses of cancer patients who died either at St Christopher's Hospice or at other hospitals in 1967-69. Hinton (1979) interviewed patients, relatives and staff at St Christopher's Hospice and at other hospitals in the early 1970s. Other hospices, set up since 1969, havę을 carried out their own research (Lack and Bucking- 3 . ham, 1978; Cameron and Parkes, 1983). The resultso of these studies indicate that hospices are more successful than other hospitals at reducing chronic $\bigcirc$ pain, depression and anxiety among late-stage cancer $\vec{N}$ patients. Several studies suggest that they also reduce $\tilde{O}$ the suffering of the patient's family.

The aim of the present study was to evaluate thechanges that have occurred at St Christopher's and T other local hospitals over a period of 10 years since음 1969. The provision of a Study Centre at St Christopher's Hospice to provide instruction in terminal care, the development of Home Care Service fri $\overrightarrow{0}$ families caring for a cancer patient at home and $\mathrm{a}_{+}^{\circ}$ Bereavement Service for the after-care of many of families of patients who die in the Hospice, are someo of the innovations which may have altered the overall effects of care at St Christopher's Hospice and ato other hospitals in the vicinity.

This study attempts to measure the effects of these changes by replicating the study carried out 10 yearso previously (Parkes, 1978; 1979).

\section{Method}

As in our 1967-69 study, surviving spouses of patients 65 years of age who had died from cancer in hospitals in the London Boroughs of Lewisham and Bromley during 1977-79 were identified from the death registration forms (Table 1).

As in the earlier study and in most other studies of 5 bereaved people, a substantial number of widows and widowers had moved away from the address given on the death certificate or preferred not to be interviewed. We did not press them to participate.

The proportion of the accessible respondents who had to be excluded because their spouse had stillw been under active treatment at the time of death (i.e. there had been no period of terminal care) hado dropped from $23.3 \%$ in $1967-69$ to $16.3 \%$ in $1977-79$. $(P<0 \cdot 10)$.

One hundred and sixty-four respondents $(99$ 귬 
TABLE 1. Details of study

\begin{tabular}{lcc}
\hline & $1967-69$ & $1977-79$ \\
\hline $\begin{array}{l}\text { Death registration forms indicating } \\
\text { surviving spouse }\end{array}$ & 435 & 442 \\
$\begin{array}{l}\text { Surviving spouse dead or too ill to } \\
\text { be interviewed }\end{array}$ & 12 & 15 \\
$\begin{array}{l}\text { Patient still under active treatment } \\
\quad \text { at death (i.e. no terminal care) }\end{array}$ & 69 & 32 \\
$\begin{array}{l}\text { Surviving spouse moved away or untraceable } \\
\text { Unable to recall information } \\
\text { (usually due to multiple admissions) } \\
\quad \text { or preferred not to be interviewed }\end{array}$ & 64 & 111 \\
Interviewed for study (widows/widowers) & 107 & 120 \\
& 227 & 164 \\
& $(151 / 76)$ & $(99 / 65)$ \\
\hline
\end{tabular}

widows and 65 widowers) were interviewed in their homes about 13 months after bereavement. Of these, $42 \mathrm{had}$ been married to patients who had died at St Christopher's Hospice. Their replies to our questions are compared, in Section I below, with those of 122 spouses of patients who died in other hospitals.

The interview was semi-structured, covering the terminal illness and reactions of patient and surviving spouse to each phase of care. Particular attention was paid to the severity and duration of pain, distress and anxiety. Since these tend to fluctuate, respondents were asked to estimate the maximum and minimum intensity of each symptom on a five-point scale. Overall symptom scores were calculated as means of the 'minimum' and 'maximum' scores.

To ensure comparability between hospitals, 34 patients in each triennium who had died in St Christopher's Hospice were matched with 34 patients who had died in other local hospitals. Matching criteria were age, sex, socio-economic status, duration of terminal period (defined as the time from the end of active treatment to death) and severity of pain before terminal period. Three of these pairs were eliminated from the 1977-79 samples because one or other had died so soon after admission that the quality of hospital care could not be assessed. We then examined the matching between 1967-69 and 1977-79 samples. By eliminating one more pair from the 1977-79 sample, it was possible to obtain good matching on age, sex and duration of terminal period. A change in the method of recording socioeconomic status and the small amounts of pain prior to the terminal period reported in the 1977-79 sample precluded matching on these criteria.

Thus we were left with 30 matched pairs covering the 1977-79 period and 34 matched pairs covering 1967-69. The results of this comparison are shown in section II below.

\section{Results}

\section{Before terminal period}

The demographic features of the unmatched samples are similar in the two settings. There were no significant differences between patients admitted to St Christopher's Hospice and other hospitals in age, sex, socio-economic status and severity of pain, implying that the two settings have adopted similar admission criteria. Table 2 shows that patients admitted to St Christopher's Hospice in 1977-79 were, on average, 7 years older than patients admitted in 1967-69 (a trend confirmed by the Hospice's own admission statistics).

While the demographic characteristics have changed little, the symptoms suffered before the terminal period have changed a great deal. Patients in 1977-79 were reported to have suffered less severe overall pain prior to the terminal period than in $1967-69(P<0.01)$, and even more striking is the decline in the proportion of patients in both settings who were said to have suffered severe overall distress (St Christopher's Hospice $P<0.01$, other hospitals $P<0.001$ ). Along with this improvement is a decline in the proportion of surviving spouses who reported severe overall anxiety during this period (St Christopher's Hospice $P<0.002$, other hospitals $P<0.001$ ).

These figures refer to the time before the end of active treatment. There was a substantial group of patients who were nursed at home for varying periods of time between the end of active treatment and admission to hospital or hospice. Within this sub-sample there was evidence that fewer patients suffered overall pain at home rated as 'very severe' or 'extreme' in 1977-79 than in 1967-69. But the proportion with overall pain at home rated as 'severe' remains higher by comparison with the periods of care in hospital which preceded or followed (further details will be published elsewhere).

\section{After admission for terminal care}

The matched samples enabled comparisons to be made between settings and years during the final phase of care in hospital. 
TABLE 2. Mean age and symptoms before terminal period (unmatched samples)

\begin{tabular}{|c|c|c|c|c|}
\hline & St Christopher's & Other hospitals & St Christopher's & Other hospitals \\
\hline Mean age (years) of respondent & $49 \cdot 9$ & $55 \cdot 0$ & $56 \cdot 7$ & $53 \cdot 7$ \\
\hline \multicolumn{5}{|l|}{ Patient before terminal period } \\
\hline \multicolumn{5}{|l|}{ Respondent before terminal period } \\
\hline Overall anxiety severe $(\%)$ & 78 & 61 & 44 & 30 \\
\hline
\end{tabular}

\section{Relationship of patient and family to hospital}

In 1969 only $6 \%$ of patients entering St Christopher's Hospice had any previous knowledge of the place. By 1979 this proportion had risen to $77 \%$ $(P<0.001)$. Patients entering other local hospitals were more likely to have previous knowledge in both years $(79 \%$ and $82 \%)$.

The patient's spouse spent longer at the bedside at St Christopher's Hospice than at other hospitals and at St Christopher's there was a significant increase over the 10-year period in the proportion of respondents who helped care for the patient (47\% in 1969 , $85 \%$ in $1979, P<0.01)$. At other hospitals by 1979 there was a tendency for spouses to spend longer at the bedside than they did in 1969 , but only a quarter of them were permitted to help care for the patient.

As in 1969, ward sisters and nurses in both settings were seen as 'approachable', 'friendly', 'helpful' and 'efficient', but there was a significant drop in the proportion of ward sisters who were seen as 'very busy', from $60 \%$ to $15 \%$ at St Christopher's Hospice $(P<0.002)$ and from $92 \%$ to $64 \%$ elsewhere $(P<0.05)$.

The trend found in 1969 for spouses of patients who died at St Christopher's to have spoken to more 'other staff' than at other hospitals had increased by 1979. In particular, $85 \%$ now recalled the hospital receptionist (3\% at other hospitals) and $76 \%$ recalled a ward orderly (3\% at other hospitals).

As before, most respondents took a positive view of clergy visits, ward prayers and religious services which are regular occurrences at the Hospice, but seldom said to occur at other hospitals.

After the patient's death the proportion of respondents who had kept in touch with someone from St Christopher's Hospice had risen from 24\% in 1969 to $66 \%$ in $1979(P<0.002)$. Some of this contact had been made by a volunteer visitor from the hospice's Family Service, whose role it is to visit bereaved people in their homes and help them with any problems arising out of their bereavement. Of 15 who had maintained contact with the hospice, 14 had found this helpful, and one had mixed feelings. Noge had found it unhelpful.

No respondent whose spouse had died in anotheे hospital had kept in contact after bereavement if either $1967-69$ or $1977-79$.

\section{Changes in the patient}

Table 3 shows the ways in which the severity $\frac{\mathbb{O}}{\mathrm{Of}}$ reported symptoms had changed over the 10 years of the study.

The most striking finding is a decline bet 1967-69 and 1977-79 in the proportion of patien at other hospitals who were thought to have sufferge severe overall pain $(P<0.05)$, continuous pat $(P<0.05)$, severe distress $(P<0.05)$ or continuogeds distress (NS). There has also been a decline in the amount of reported continuous pain $(P<0.05)$ a a severe distress $(P<0.05)$ suffered by patients at $\$$ Christopher's Hospice, but the improvement at othor hospitals has been so great there was no longer, by 1979, any significant difference between St Christopher's Hospice and other hospitals in respect of ay of these measures.

This improvement has not been brought about rendering the patient unconscious. On the contras., patients in both settings are now said to be rather less often confused or unconscious than they were in 1967-69 (not significant).

As shown elsewhere (Parkes, 1980) the advent of the Home Care Service was associated with considerable drop in the median length of stay on the wards at St Christopher's Hospice and may accouft for the finding that patients at the Hospice are now less likely to be fit enough (not significant) to get ongt of bed to go to the toilet than they were in 1967-6ु; (if they had been, they would probably have stayed at home). Even so, patients admitted to St Christopheट्]s are still less likely to be confined to bed than they ape at other hospitals $(P<0.05)$.

There was no significant change in the patien $\overrightarrow{f s}$ 
TABLE 3. Symptoms during the period in hospice or hospital which ended with death of patient. (matched sub-samples) (all figures are percentages)

\begin{tabular}{|c|c|c|c|c|}
\hline & \multicolumn{2}{|c|}{$1967-69$} & \multicolumn{2}{|c|}{$1977-79$} \\
\hline & $\begin{array}{c}\text { St Christopher's } \\
(n=34)\end{array}$ & $\begin{array}{l}\text { Other hospitals } \\
\quad(n=34)\end{array}$ & $\begin{array}{c}\text { St Christopher's } \\
(n=30)\end{array}$ & $\begin{array}{l}\text { Other hospitals } \\
\quad(n=30)\end{array}$ \\
\hline \multicolumn{5}{|l|}{ Overall pain: } \\
\hline Extreme or very severe & 4 & 19 & 0 & 0 \\
\hline Severe & 12 & 9 & 7 & 4 \\
\hline Mild to moderate & 54 & 48 & 60 & 68 \\
\hline None & 30 & 24 & 33 & 28 \\
\hline \multicolumn{5}{|l|}{ Continuity pain: } \\
\hline Continuous or mostly continuous & 35 & 50 & 10 & 19 \\
\hline \multicolumn{5}{|l|}{ Overall distress: } \\
\hline Severe or greater & 10 & 37 & 0 & 0 \\
\hline \multicolumn{5}{|l|}{ Continuity distress: } \\
\hline Continuous or mostly continuous & 0 & 19 & 0 & 4 \\
\hline \multicolumn{5}{|l|}{ Rationality: } \\
\hline Very confused or unconscious & 56 & 75 & 30 & 45 \\
\hline \multicolumn{5}{|l|}{ Mobility: } \\
\hline Mostly in bed & 61 & 88 & 74 & 96 \\
\hline
\end{tabular}

awareness of diagnosis or prognosis in either setting with about a third in each said to have been fully aware of their prognosis and a slightly larger proportion aware of their diagnosis.

\section{Changes in the patient's spouse}

Our three measures of the respondent's reactions during the period of terminal care in hospital tend to show some decrease in anxiety and worry over the 10 years, but only two of them, a check-list of likely sources of anxiety which included worry about unrelieved pain $(P<0.05)$ and a list of symptoms that commonly accompany anxiety and stress $(P<0.002)$, reached statistical significance, and that was at other hospitals only (Table 4).

Even so the proportion of respondents who showed 'very great' anxiety during the final phase in 1977-79 at St Christopher's Hospice was significantly less than at other hospitals $(P<0.05)$. The reported intensity of features of post-bereavement grief and distress experienced by the widow or widower after the patient's death also dropped significantly between 1969 and 1979 in both settings (St Christopher's $P<0.05$; other hospitals $P<0.002$ ).

When asked which of six attributes describe the institution, respondents answered that St Christopher's Hospice is characterized by 'The Hospital is like a family' $(P<0.001$ in both $1967-69$ and 1977-79) and 'Don't worry' (1967-69 $P<0.01$; 1977-79 NS); other hospitals by 'Leave it to us'
(1967-69 NS, 1977-79 $P<0 \cdot 01$ ). In both settings there is agreement that 'Nothing is too much trouble'.

\section{Discussion and conclusions}

Since much of the improvement in pain relief before and after admission for terminal care is a consequence of the work of Saunders and other proponents of hospice approaches, it is no criticism of St Christopher's Hospice that we were no longer able to demonstrate any statistically significant difference between the amount of pain experienced in the hospice by comparison with other hospitals. In neither setting is unrelieved pain now a major problem.

By 1979 spouses were playing a larger part in the care of the patient at St Christopher's Hospice; they were getting to know more members of ancillary staff and nearly two-thirds were remaining in touch with hospice staff or the volunteer counsellors of the Family Service after the patient's death. No such changes were reported by spouses of patients dying at other hospitals despite a significant increase in the time which spouses now spend at the bedside.

It is likely that these changes in both settings account for the reductions in the amount of distress which were experienced by the patient and family before bereavement and better adjustment afterwards in 1977-79 than was found in 1967-69. Both types of institution are also now seen as taking over and relieving the worries of the family more than 
TABLE 4. Emotional reactions and attitudes of respondents in matched samples during and after final phase in hospice or hospital, 1967-69 and 1977-79

\begin{tabular}{|c|c|c|c|c|}
\hline & \multicolumn{2}{|c|}{$1967-69$} & \multicolumn{2}{|c|}{$1977-79$} \\
\hline & $\begin{array}{l}\text { St Christopher's } \\
(n=34)\end{array}$ & $\begin{array}{l}\text { Other hospitals } \\
\quad(n=34)\end{array}$ & $\begin{array}{l}\text { St Christopher's } \\
(n=30)\end{array}$ & $\begin{array}{l}\text { Other hospitals } \\
\quad(n=30)\end{array}$ \\
\hline \multicolumn{5}{|l|}{$\begin{array}{l}\text { Emotional reactions } \\
\text { of respondents during final } \\
\text { phase in hospital } \\
\text { Anxiety (\%) }\end{array}$} \\
\hline Very great & 23 & 46 & 13 & 46 \\
\hline Great & 45 & 36 & 57 & 35 \\
\hline Less & 32 & 18 & 29 & 19 \\
\hline Worry score during & & & & \\
\hline $\begin{array}{l}\text { final phase (median) } \\
\text { Stress symptom score }\end{array}$ & 4 & $8 \cdot 5$ & 5 & 5 \\
\hline during final phase (median) & $10 \cdot 5$ & 13 & 9 & 8 \\
\hline $\begin{array}{l}\text { Post-bereavement grief score } \\
\text { (median) }\end{array}$ & 14 & 12 & $8 \cdot 5$ & $6 \cdot 5$ \\
\hline $\begin{array}{l}\text { Attitude to institution } \\
\text { Which phrases describe } \\
\text { the institution? }(\%) \\
\text { 'Nothing is too much }\end{array}$ & & & & \\
\hline $\begin{array}{l}\text { trouble' } \\
\text { 'The hospital is }\end{array}$ & 100 & 59 & 100 & 88 \\
\hline a family' & 78 & 11 & 87 & 8 \\
\hline 'Don't worry' & 41 & 11 & 65 & 46 \\
\hline 'Leave it to us' & 26 & 33 & 60 & 85 \\
\hline 'Never give up' & 22 & 15 & 10 & 27 \\
\hline 'Efficiency comes first' & 22 & 37 & 20 & 56 \\
\hline
\end{tabular}

they did in 1967-69. But they have achieved this in rather different ways - at St Christopher's by allowing the patients' spouses to share in the care of the patient and by improving contact and support to them before, during and after the period of terminal care, and at other hospitals by providing efficient and effective care for the patients, with some extension of visiting hours but without including the family in the caring team.

The use of hospices and similar special units as teaching centres, as recommended by Wilkes' Working Party (1980), is supported by the current study which shows marked improvements in patients and their spouses in two boroughs adjacent to the Study Centre at St Christopher's Hospice. This can be attributed to improvements in patient-care. It is also worth noting that increased recognition of these improvements may explain the decline in the number of patients who were kept on active treatments (with all the unpleasant side effects to which these often give rise) until the end of their lives.

The spouses of patients dying in St Christopher's Hospice reported less anxiety than spouses of patients dying elsewhere, and it seems very likely that this results from the greater engagement with the family that is now a hallmark of care at St Christopher's Hospice. Our re-evaluation confirms that, as in 1967-69, St Christopher's Hospice is 'like a family'.

\section{Acknowledgments}

Thanks are due to Cynthia Coleman who carried out all the interviews, to John Hughes for assistance with the statistical analysis to the Office of Statistical Censuses for providing us with non? confidential parts of the death registration certificates, to $C$. Mh Saunders, R. Twycross, T. West and T. Walsh for commenting of the drafts of this paper, and to the widows and widowers whळ generously shared with us their recollections of a very painful period of their lives.

\section{References}

CAmeron, J. \& PARKes, C.M. (1983) Terminal care: evaluation of effects on surviving family of care before and after bereavemen? Postgraduate Medical Journal, 59, 73.

Hinton, J. (1979) Comparison of places and policies for termina care. Lancet i, 29.

LaCK, S.A. \& Buckingham, R.W. (1978) First American Hospice Three Years of Home Care. Hospices Inc., 765 Prospect St. New Haven, Ct. 06511.

PARKES, C.M. (1978) Home or hospital? Terminal care as seen b? surviving spouses. Journal of Royal College of General Practition ers, 12, 19.

PARKES, C.M. (1979) Terminal care: Evaluation of in-patienservices at St Christopher's Hospice. I. Views of surviving spousefy on effects of the service on surviving spouses. Postgraduate Medical Journal, 55, 517.

PARKES, C.M. (1980) Terminal care: Evaluation of an advisorou domiciliary service at St Christopher's Hospice. Postgraduate Medical Journal, 56, 685.

WILKES, E. (1980) Report of the Working Group on Terminal Care Standing Medical Advisory Committee, Dept. Health \& Socif Security, London.

(Accepted 29 June 1983) 